\title{
Influence of inductance induced noise in an YBa2Cu307 dc-SQUID at high operation temperatures
}

\author{
Nilsson, P. Å.; Claeson, T.; Hansen, J. B.; Kyhle, Anders
}

Published in:

Applied Physics Letters

Link to article, DOI:

10.1063/1.111594

Publication date:

1994

Document Version

Publisher's PDF, also known as Version of record

Link back to DTU Orbit

Citation (APA):

Nilsson, P. A.., Claeson, T., Hansen, J. B., \& Kyhle, A. (1994). Influence of inductance induced noise in an YBa2Cu3O7 dc-SQUID at high operation temperatures. Applied Physics Letters, 64(18), 2445-2447. https://doi.org/10.1063/1.111594

\section{General rights}

Copyright and moral rights for the publications made accessible in the public portal are retained by the authors and/or other copyright owners and it is a condition of accessing publications that users recognise and abide by the legal requirements associated with these rights.

- Users may download and print one copy of any publication from the public portal for the purpose of private study or research.

- You may not further distribute the material or use it for any profit-making activity or commercial gain

- You may freely distribute the URL identifying the publication in the public portal 


\title{
Influence of inductance induced noise in an $\mathrm{YBa}_{2} \mathrm{Cu}_{3} \mathrm{O}_{7}$ dc-SQUID at high operation temperatures
}

\author{
P. A. Nilsson and T. Claeson \\ Department of Physics, Chalmers University of Technology, S-412 96 Göteborg, Sweden
}

J. B. Hansen

NKT Research Center, Sognevej 11, DK-2605 Bröndby, Denmark

A. Kühle

Physics Department, Technical University of Denmark, DK-2800 Lyngby, Denmark

(Received 8 November 1993; accepted for publication 9 February 1994)

\begin{abstract}
The voltage modulation depth of a high $T_{c}$ dc-SQUID was measured at temperatures close to $T_{c}$ and compared to a model by Enpuku et al. where the flux noise from the SQUID inductance is taken into account. The device was an $\mathrm{YBa}_{2} \mathrm{Cu}_{3} \mathrm{O}_{7}$ dc-SQUID made on a bicrystal substrate of $\mathrm{SrTiO}_{3}$. The design was of the Ketchen square-washer type with an inductance of $67 \mathrm{pH}$. Measurements were made in a temperature interval from 75 to $87 \mathrm{~K}$, where the voltage modulation depth changed from 4.5 to $1.4 \mu \mathrm{V}$ in close agreement with the model.
\end{abstract}

Superconducting quantum interference devices (SQUIDs) have been made of high $T_{c}$ materials by many groups now, and low noise has been achieved at liquid nitrogen temperature both in the white ${ }^{1}$ and $1 / f$ noise regimes. ${ }^{2,3}$ At this high temperature, it is important to understand how the thermal noise affects the behavior of the SOUID, the $k_{B} T$ value is 18 times higher at $77 \mathrm{~K}$ compared to $4.2 \mathrm{~K}$. This high thermal noise creates excess voltage in the Josephson junctions of the SQUID and causes noise rounding in the current-voltage characteristics. The effect has been studied by Gross et al. ${ }^{4}$ for grain boundary junctions in $\mathrm{YBa}_{2} \mathrm{Cu}_{3} \mathrm{O}_{7}$, and the results were in good agreement with the Ambegaokar-Halperin (AII) model. ${ }^{5}$ Another effect of the thermal noise that has been less studied is the effect of noise flux generated by noise currents in the SQUID loop arising from thermal noise in the junctions. However, in a recent paper by Enpuku et al. ${ }^{6}$ this effect was treated and calculations showed that this noise source lowers the voltage modulation depth of the SQUID when the SQUID inductance is high. This is important for practical SQUID applications because a moderately large area, and hence a high inductance, is necessary for SQUIDs designed to be coupled to the outside world through a flux transformer.

An analytical expression for the voltage modulation was given: ${ }^{6}$

$$
\Delta V=\frac{7}{\pi^{2}} \frac{I_{c} R_{n}}{1+\beta}\left(1-3.57 \frac{\sqrt{k_{B} T L}}{\Phi_{0}}\right) .
$$

$I_{c}$ and $R_{n}$ are the critical current and normal resistance of the Josephson junctions in the SQUID, $\beta=2 L I_{c} / \Phi_{0}$ is the screening . parameter, ${ }^{7} L$ is the SQUID inductance, and $\Phi_{0}=h / 2 e$ is the flux quantum. The theoretical expression was compared to experimental work and a rather good agreement was found, but with some scatter. ${ }^{6}$ Similar results have also been scen by the Berkelcy group. ${ }^{8}$ To further elucidate the issue, which is important for the correct modeling of a SQUID at these temperatures, we made a dc-SQUID of $\mathrm{YBa}_{2} \mathrm{Cu}_{3} \mathrm{O}_{7}$ (YBCO) that could be operated close to the critical temperature of the material and with well defined param- eters. This SQUID was then used for measurements of the temperature dependence of the voltage modulation depth close to $T_{c}$.

The SQUID was designed to be optimal at $77 \mathrm{~K}$ operation. A number of design rules have to be followed. The critical current for a junction should give a Josephson coupling energy that is much larger than the thermal energy. Earlier work ${ }^{9}$ has shown that a factor of 5 in difference is sufficient. This gives a minimum critical current of $16 \mu \mathrm{A}$ at $77 \mathrm{~K}$. This current, taken together with the requirement that $\beta$ should be close to 1 , gives a maximum SQUID inductance of $64 \mathrm{pH}$. We designed a SQUID of the traditional Ketchen type ${ }^{10}$ from these requirements.(Fig. 1). A hole diameter $d$ of $20 \mu \mathrm{m}$ and a slit length of $120 \mu \mathrm{m}$ were chosen. This gives an estimated ${ }^{11}$ SQUID inductance of $L_{\text {hole }}+L_{\text {slit }}=31 \mathrm{pH}+36$ $\mathrm{pH}=67 \mathrm{pH}$, where $L_{\text {bole }}=1.25 \mu_{0} d$ and $L_{\text {slit }}=0.3 \mathrm{pH} / \mu \mathrm{m}$.

The SQUID was made on a bicrystal, where the critical currents of the junctions could be controlled by selecting an appropriate bicrystal misorientation and junction size. ${ }^{12} \mathrm{~A}$ bicrystal of (001) oriented $\mathrm{SrTiO}_{3}$ with an in-plane misorientation angle of $36.8^{\circ}$ was chosen for the experiment. A grain boundary with this misorientation angle in a YBCO film has a critical current density of $10^{3} \mathrm{~A} / \mathrm{cm}^{2}$, which implies a junc-

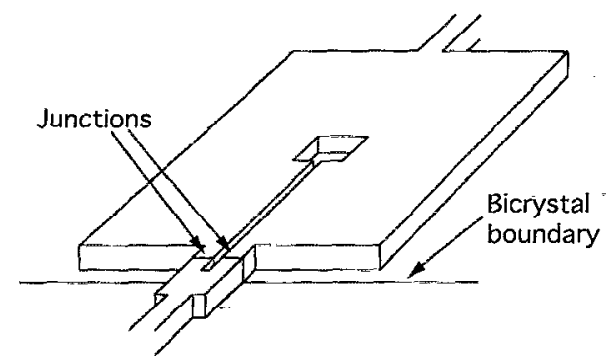

FIG. 1. The SOUID was made using the square-washer Ketchen design with an $\mathrm{YBa}_{2} \mathrm{Cu}_{3} \mathrm{O}_{7}$ film deposited on a bicrystal $\mathrm{SrTiO}_{3}$ substrate. The center hole side is $20 \mu \mathrm{m}$ and the slit is $120 \mu \mathrm{m}$ long. This gives a SQUID inductance of $67 \mathrm{pH}$. The Josephson junctions, on top of the bicrystal boundary, are $8 \mu \mathrm{m}$ wide. 


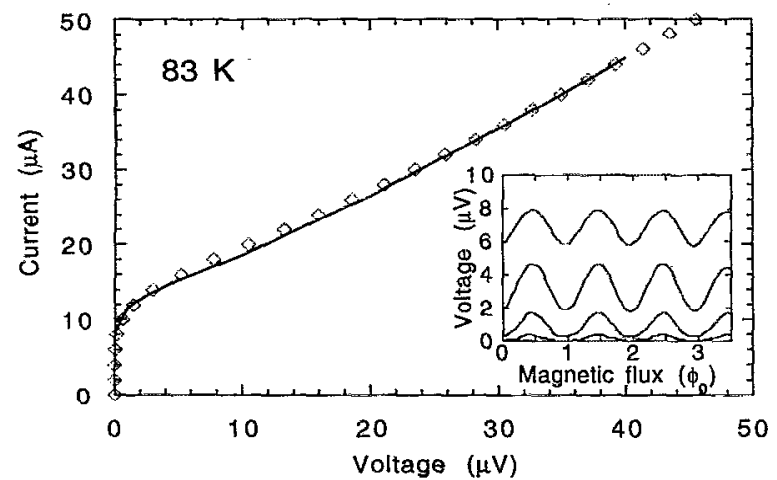

FIG. 2. The $I-V$ curve for the SQUID junctions at $83 \mathrm{~K}$ corresponded to the RSJ model. The AH fit is shown by the diamonds. The inset shows some $V$ vs $\Phi$ curves for the SQUID for this temperature at different bias points.

tion width of $8 \mu \mathrm{m}$ to achieve a critical current of $16 \mu \mathrm{A}$ in a $200 \mathrm{~nm}$ thick film. The chip was made in a standard photolithographic process. Briefly, the processing steps were the following:

(i) Alignment marks of $\mathrm{BaF}_{2}$ were deposited on the bicrystal substrate by thermal evaporation through a liftoff stencil to allow for alignment of the junctions relative to the bicrystal boundary.

(ii) A $200 \mathrm{~nm} c$-axis oriented epitaxial film of YBCO was deposited by a standard laser deposition process. ${ }^{13}$ The film was covered with a $40 \mathrm{~nm}$ layer of gold that was in situ laser deposited on the YBCO film to ensure low contact resistance and to protect the YBCO from resist contamination. The $\mathrm{Au} / \mathrm{YBCO}$ layer was then patterned with photolithography and Ar ion milling.

(iii) A contact layer for bonding (15 nm Cr+250 nm Au) was deposited by thermal evaporation through a liftoff mask.

(iv) An additional brief ion milling step was used to remove the parts of the in situ gold layer that were shunting the junctions. This process gave the possibility of aligning the junctions to the bicrystal boundary with an accuracy of about $1 \mu \mathrm{m}$. It was also easy to connect the SQUID to the measurement setup with gold wire bonding.

The measurements were performed in a magnetically shielded liquid helium cryostat in an electromagnetically screened room. The current-voltage $(I-V)$ curves of the SQUID were in agreement with the resistively shunted junction (RSJ) model (Fig. 2), and a response to magnetic field could be seen up to temperatures close to $T_{c}(90 \mathrm{~K})$. The washer of the SQUID was measured to focus the magnetic field six times, as deduced from the period of the response compared to the hole and slit area of the SQUID. The maximum critical current of the SQUID at $77 \mathrm{~K}$ was $76 \mu \mathrm{A}$ with a $1 \mu \mathrm{V}$ criterion. This implies a junction critical current of 38 $\mu \mathrm{A}$, about two times the design value of $16 \mu \mathrm{A}$. The critical current is a strong function of the temperature this close to $T_{c}$ (Fig. 3), which explains the deviation.

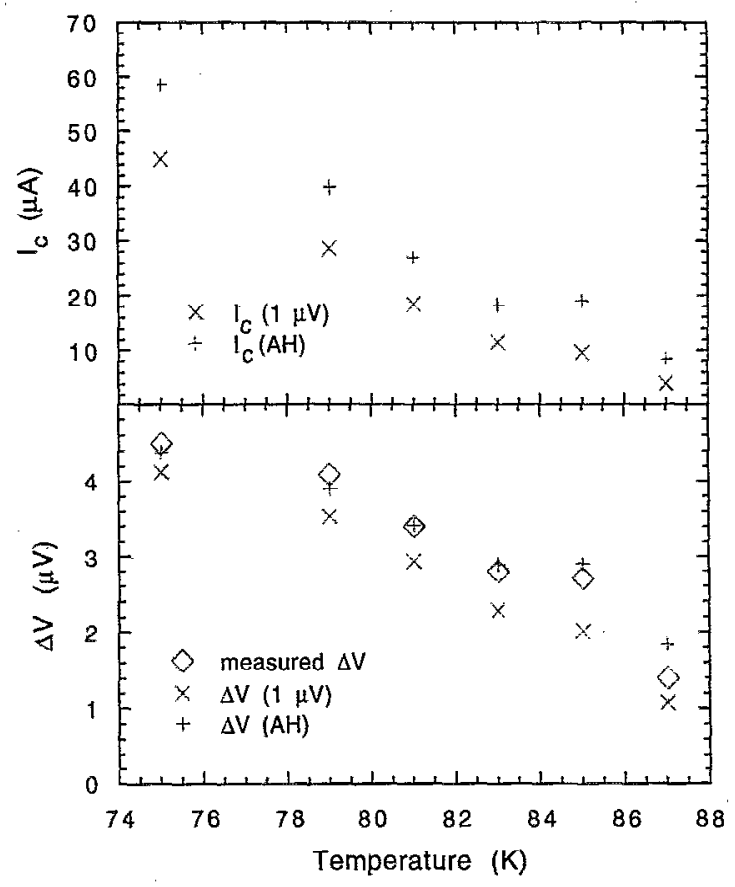

FIG. 3. In the upper graph, the junction critical currents $I_{\mathrm{c}}$ (one half times the measured SQUID values) are shown. Both values from a $1 \mu \mathrm{V}$ criterion and values achieved from fits to the AH model are shown. The $I_{c}$ values are used to calculate the voltage modulation depth $\Delta V$ from the theory by Enpuku et al. (lower graph). Both calculated values from a $1 \mu \mathrm{V}$ criterion $[\Delta V(1 \mu V)]$ and from the $A H$ model $[\Delta V(\mathrm{AH})]$ are shown. They are compared to the measured $\Delta V$ values.

The voltage modulation depth $\Delta V$ was measured at several temperatures from 75 to $87 \mathrm{~K}$. The bias current of the SQUID was adjusted to give the maximum voltage modulation depth for a given temperature. The values are shown in Fig. 3, where they are compared to the theoretical values from Eq. (1). In the calculation of the theoretical values the cstimated inductance of $67 \mathrm{pH}$ and measured critical currents with a $1 \mu \mathrm{V}$ criterion or critical current values calculated from the AH model were used. As can be seen from Fig. 3, the agreement with the calculations from Eq. (1) is good. Note that there are no free parameters that are fitted to the data. The calculations underestimate the voltage modulation depth when the $1 \mu \mathrm{V}$ criterion is used. A better fit is achieved if the critical current is calculated from the $I-V$ curves with the AH model. The $1 \mu \mathrm{V}$ criterion underestimates the "real" $I_{c}$ values of the $\mathrm{AH}$ model slightly.

The noise of the SQUID at $77 \mathrm{~K}$ was measured with standard flux-locked SQUID electronics. A field modulation signal of $100 \mathrm{kHz}$ was used to modulate the SQUID at $\Phi_{0} / 4$. The voltage response was demodulated and connected to a spectrum analyzer. The white noise level of the SQUID was $1.2 \times 10^{-9} \Phi_{0}^{2} / \mathrm{Hz}$, which corresponds to an energy resolution of $3.8 \times 10^{-29} \mathrm{~J} / \mathrm{Hz}$. This can be compared to the theoretical white noise limit: ${ }^{14}$

$$
S_{\Phi}(f)=\frac{S_{v}(f)}{(d V / d \Phi)^{2}}=\frac{\left[1+\frac{1}{2}\left(I_{c} / I\right)^{2}\right]\left(4 k_{B} T R_{d}^{2} / R_{n}\right)}{(d V / d \Phi)^{2}} .
$$

$S_{\Phi}(f)$ is the flux noise, $S_{v}(f)$ the voltage noise, $d V / d \Phi$ the 
transfer function of the SQUID, and $I$ and $R_{d}$ the current and dynamic resistance of the Josephson junctions at the bias point. For our parameters for the $79 \mathrm{~K}$ measurement, the theoretical white noise limit was $3.2 \times 10^{-10} \Phi_{0}^{2} / \mathrm{Hz}$. This is within an order of magnitude of the measured noise value. The crossover frequency to $1 / f$ noise was at $260 \mathrm{~Hz}$. The low noise level ensures us that no external noise, lowering the voltage modulation depth, is coupled to the SQUID. Hence, any discrepancy between the model and the experimental data must be accounted for in the model.

In conclusion, we have checked the theory for the reduction of the voltage modulation depth due to flux noise from the SQUID inductance that was published recently by Enpuku et $a l^{6}{ }^{6}$ The SQUID used for the test was a bicrystal SQUID of the Ketchen design made in a YBCO film that was optimized for $77 \mathrm{~K}$ operation. The behavior of this low noise SQUID was close to the theoretical predictions, which means that our measurements verify the theory and it can he used for further modelling and optimizations of SQUIDs at high temperatures. The results also emphasize the importance of accounting for different inductances when noise data for SQUIDs taken at temperatures in the $77 \mathrm{~K}$ range are compared.

We would like to thank Z. G. Ivanov, G. Brorsson, and
C. S. Jacobsen for fruitful discussions and help in the film preparation. This work was supported by the European Space Agency under ESTEC Contract No. 9031/90/NL/PB(SC).

${ }^{1}$ M. Kawasaki, P. Chaudhari, T. H. Newman, and A. Gupta, Appl. Phys. Lett. 58, 2555 (1991).

${ }^{2}$ H. K. Olsson, P. A. Nilsson, Z. Ivanov, R. H. Koch, E. A. Stepantsov, and A. Y. Tzalenchuk, Appl. Phys. Lett. 61, 861 (1992).

${ }^{3}$ G. Friedl, G. Daalmans, M. Vildic, D. Uhl, F. Bömmel, B. Roas, B. Hillenbrand, B. Stritzker, and H. E. Hoenig, IEEE Trans. Appl. Supercond. 3, 2018 (1993).

${ }^{4}$ R. Gross, P. Chaudhari, D. Dimos, A. Gupta, and G. Koren, Phys. Rev. Lett. 64, 228 (1990).

${ }^{5}$ V. Ambegaokar and B. I. Halperin, Phys. Rev. Lett. 22, 1364 (1969).

${ }^{6} \mathrm{~K}$. Enpuku, Y. Shimomura, and T. Kisu, J. Appl. Phys. 73, 7929 (1993).

${ }^{7}$ C. D. Teche and J. Clarke, J. Low Temp. Phys. 29, 301 (1977).

${ }^{8}$ D. Koelle, A. H. Miklich, F. Ludwig, E. Dantsker, D. T. Nemeth, and J. Clarke, Appl. Phys. Lett. 63, 2271 (1993).

${ }^{9}$ J. Clarke and R. H. Koch, Science 242, 217 (1988).

${ }^{10}$ M. B. Ketchen and J. M. Jaycox, Appl. Phys. Lett. 40, 736 (1982).

${ }^{11}$ M. B. Ketchen, IEEE Trans. Magn. 27, 2916 (1991).

${ }^{12}$ Z. G. Ivanov, P. A. Nilsson, D. Winkler, J. A. Alarco, T. Claeson, E. A. Stepantsov, and A. Y. Tzalenchuk, Appl. Phys. Lett. 59, 3030 (1991).

${ }^{13} \mathrm{G}$. Brorsson, Z. Ivanov, and P. $\AA$. Nilsson, Science and Technology of Thin Film Superconductors 2, edited by R. D. McConnell and R. Noufi (Plenum, New York, 1990), p. 169.

${ }^{14}$ J. Clarke, Superconducting Devices, edited by S. T. Ruggiero and D. A. Rudman (Academic, Boston, 1990), p. 51. 